\title{
Curcumin gum Arabic nanoparticles demonstrate potent antioxidant and cytotoxic properties in human cancer cells
}

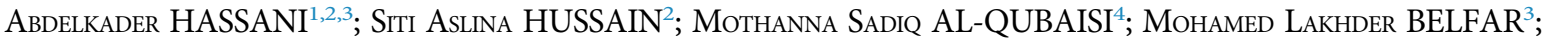 \\ HaKim BELKHALFA ${ }^{5}$; Hamid Hammad ENEZEI ${ }^{6}$; Hamid ZENTOU²; Wisam Nabeel IBRAHIM ${ }^{7,8, *}$; AbD Almonem DOOLAANEA ${ }^{1, *}$ \\ ${ }^{1}$ Department of Pharmaceutical Technology, Faculty of Pharmacy, International Islamic University Malaysia, Kuantan, Malaysia \\ 2 Department of Chemical and Environmental Engineering, University Putra Malaysia, Serdang, 43400, Malaysia \\ ${ }^{3}$ Department of Chemistry, Faculty of Mathematics and Material Sciences, University of kasdi Murbah, Ouargla, Algeria \\ ${ }^{4}$ UPM-MAKNA Cancer Research Laboratory, Institute of Bioscience, University Putra Malaysia, Serdang, Malaysia \\ ${ }^{5}$ Scientific and Technical Research Center in Physicochemical Analysis, Bou-Ismail, Tipaza, Algeria \\ 6 Department of Oral \& Maxillofacial Surgery, College of Dentistry, University of Anbar, Ramadi, Iraq \\ 7 Department of Biomedical Sciences, College of Health Sciences, QU Health, Qatar University, Doha, Qatar \\ 8 Pharmaceutical Research Unit, QU Health, Qatar University, Doha, Qatar
}

Key words: Curcumin, Gum arabic, Nanoparticles, Cancer cells, Antioxidants

\begin{abstract}
The main purpose of the study was to enhance the stability and therapeutic effects of Curcumin (Cur) through nanoformulation with gum Arabic (GA) as a coating agent through an efficient synthetic approach. The antioxidant properties of the developed nanoparticles (Cur/GANPs) were assessed through several in vitro assays, such as $\beta$-carotene bleaching activity, DPPH, and nitric oxide scavenging activities in addition to evaluating its inhibitory activity on angiotensinconverting enzyme (ACE). The cytotoxicity of Cur/GANPs was evaluated in vitro using different types of human cancer cells including breast cancer (MCF7, MDA-MB231), liver cancer (HepG2), and colon cancer (HT29) cells. The prepared particles displayed an elliptical shape with a size ranging between $20-260 \mathrm{~nm}$ and a potential difference of $-15 \mathrm{mV}$. The Cur/GANPs exhibited significant antioxidant activity compared to free curcumin when using concentrations between $31.5 \mathrm{and} 500 \mu \mathrm{g} / \mathrm{mL}$. The Cur/GANPs also had inhibited the growth of all cancer cell lines in a proportional trend with concentrations used. Hence, the encapsulation with gum Arabic has augmented the antioxidant and anti-neoplastic effects of Curcumin. Therefore, Cur/GANPs may have effective therapeutic properties in diseases attributed to oxidative stress like cancer and hypertension.
\end{abstract}

$\begin{array}{ll}\text { Abbreviations } & \\ \text { GA: } & \text { Gum Arabic } \\ \text { Cur/GANPs: } & \text { Curcumin Gum Arabic Nanoparticles } \\ \text { Cur: } & \text { Curcumin } \\ \text { ACE: } & \text { Angiotensin-converting enzyme } \\ \text { NF-KB: } & \text { Nuclear Factor kappa-light-chain-enhancer of } \\ & \text { activated B cells }\end{array}$

\section{Introduction}

Oxidative stress is a condition that contributes to various deleterious changes in the human body as a part of the aging process or in pathological conditions like cancer and

*Address correspondence to: Wisam Nabeel Ibrahim,

w.ibrahim@qu.edu.qa; Abd Almonem Doolaanea, monem@iium.edu.my

Received: 01 April 2021; Accepted: 14 May 2021 cardiovascular diseases (Reckziegel et al., 2016). Such condition results from the accumulation of oxidative radicals to critically high levels acceding the antioxidant capacity of the body leading to adverse consequences. The oxidative radicles of oxygen include hydrogen peroxide and superoxide radicals which instigate pathological changes in the form of DNA and protein oxidation and lipid peroxidation (Hanahan and Weinberg, 2011). The impact of reactive oxygen species on the cellular DNA contributes significantly to the neoplastic transformation of cells that is characterized by the uncontrolled proliferation with the other properties of cancer cells (Prasad and Tyagi, 2017). Therefore, the use of therapeutic antioxidants provides a promising tool that may deter adverse outcomes such as cancer or cardiovascular diseases.

Curcumin, the yellow polyphenol extract of turmeric, with a wide range of therapeutic uses due to its antioxidant, antineoplastic, and anti-inflammatory properties (Gangwar et al., 2013; Chidambaram and Krishnasamy, 2014; Gupta et al., 2015; 
Amalraj et al., 2017; Fadus et al., 2017). The anticancer activities of curcumin are mostly attributed to its efficiency in reverting protein oxidation including protein kinase, tyrosine kinase, and NF-kb (Notarbartolo et al., 2005; Mondal et al., 2013; Majumder et al., 2014; Meiyanto et al., 2014). However, these therapeutic attributes are challenged by poor solubility, rapid elimination, and low bioavailability (Yin et al., 2013; Meiyanto et al., 2014).

The nanomedicine field had contributed significantly to improving the potency, lowering the toxicity margin of treatments in diseases like cancer (Hussein et al., 2012; Ibrahim et al., 2020). The applications may include increasing the precision of treatments such as radiotherapy and phototherapy (Ardakani et al., 2020; Meidanchi, 2020a; Meidanchi and Ansari, 2020; Meidanchi and Motamed, 2020). The use of nanoparticles with their unique properties may also help in overcoming the low solubility of hydrophobic agents like curcumin (Wang et al., 2013; Jafarzadeha et al., 2019).

The use of amphiphilic polymer coating may enhance the stability and may impose special surface characteristics on the active agents in the nanoformulation. Hydrophilic natural polymers have been widely used for encapsulation of hydrophobic agents like curcumin to achieve the sought properties. In this context, the use of gum Arabic as a coating material may improve the antioxidant activity of curcumin due to its additive antioxidant effect, biodegradability, biocompatibility, and its chemical properties that may improve the precision of the treatment (Sarika et al., 2014).

Gum Arabic (GA), is a polysaccharide polymer that is naturally produced from the branches and stems of Leguminosae Acacia Senegal and is commonly used in many pharmaceutical and food applications (Butstraen and Salaün, 2014; Bae et al., 2019; Pieczykolan and Kurek, 2019). The highly branched molecular structure of GA induces steric repulsion properties and enhanced the in vivo stability of nanoparticles, whereas the carboxyl groups can easily react with bioactive agents (Wu and Chen, 2010). Among its many properties, its strong antioxidant property is the most documented characteristic. As a polymeric nanoparticle with special physical and chemical properties, GA is a promising candidate nanoparticle for various biomedical preparations (Al-Mosawi, 2002; Meidanchi, 2020b; Raikos et al., 2016).

In this study, a novel nanoformulation was improved based on gum arabic to enhance the antineoplastic effects of curcumin (Cur/GANPs). Hence, the Cur/GANPs were formulated using the freeze-drying method. Multiple assays were used to evaluate and validate the antioxidant potential of Cur/GANPs and Cur. The cytotoxicity of both free curcumin and Cur/GANPs was individually determined in different cancer cell lines at various time and dose intervals based on the MTT assay.

\section{Materials and Methods}

\section{Materials}

Gum Arabic (ENNASR Co., Sudan), Curcumin (Biolutions Resources, China), RAW 264.7, MCF7, HepG2, HT29, and MDA-MB231 (American Type Culture Collection (ATCC), USA). Dexamethasone, 1,1-diphenyl-2-picrylhydrazyl (DPPH), TROLOX, Linoleic acid, Hippuryl-histidyl-leucine sulfonamide, sodium nitrite, Angiotensin-converting enzyme, N-(1-naphtyl) ethylenedyamine dihydrochloride and high glucose Dulbecco's
Modified Eagle's (DMEM)(Sigma-Aldrich, Malaysia). $\beta$-carotene and Tween 80 (R\&M Co., China).

\section{Formulation of Cur/GANPs}

Cur/GANPs were prepared based on the freeze-drying method (Abdelwahed et al., 2006; Hassani et al., 2020). Briefly, the gum Arabic solution was produced by adding $0.70 \mathrm{~g}$ of GA and dissolving it in $50 \mathrm{~mL}$ of distilled water. Then, an aqueous solution of curcumin) $1 \mathrm{mg} / \mathrm{mL}$ ) was dissolved in ethanol and mixed with the GA solution in a ratio of 1:4. The mixture obtained was further to a stirring for $72 \mathrm{~h}$ then subjected to a high-pressure homogenizer (HPH) (1000 bar, 8 cycles) and frozen at $-80^{\circ} \mathrm{C}$. The resulting dispersion was then freeze-dried using a freeze dryer for $24 \mathrm{~h}$ at $-55^{\circ} \mathrm{C}$.

\section{Characterization of Cur/GANPs}

The structural properties and crystallinity of Cur/GANPs samples were assessed by the X-ray diffraction (XRD) (Shimadzu refractometer, Philips) with $\mathrm{CuKa}$ incident beam. The XRD analysis was carried out at $2 \theta=20^{\circ}-60^{\circ}$ and a scan speed of $2^{\circ}$ per minute.

The electrical potential and the size distribution of Cur/GANPs were determined in this study using the Zeta Sizer (UK) and UTHSCSA Image software. Transmission electron microscopy (TEM) of Cur/GANPs was conducted using Hitachi H-7100 electron microscope (Japan) to observe the sizes and assess the homogeneity of Cur/GANPs.

Size distribution, zeta potential, and stability of Cur/GANPs The size distribution and zeta potential of Cur/GANPs was investigated by using a zeta sizer (Malvern Nano-ZS90, London, UK). Then, $02 \mathrm{~mL}$ of samples were diluted in $08 \mathrm{~mL}$ of deionized water then subjected to ultrasonic vibration to avoid the phenomenon of aggregation of nanoparticles.

The stability study was assessed based on the changes observed in the zeta potential and size distribution of Cur/GANPs. The stability assay was carried out after 10 days of preparation of Cur/GANPs at three temperatures of storage $\left(-20^{\circ} \mathrm{C}, 4^{\circ} \mathrm{C}\right.$, and $\left.25^{\circ} \mathrm{C}\right)$. The measurement was performed in triplicate.

\section{Controlled release study of curcumin from GANPs into suitable} media by UV-Vis spectrometer

The amount of Cur released from Cur/GANPs in the buffer solutions was recorded based on Perkin Elmer UV-Vis spectrophotometer at $\mathrm{pH} 7.4$ and $\mathrm{pH}$ 4.8. The kinetic release was investigated by the addition of $8 \mathrm{mg}$ of Cur/GANPs into the buffer solution under shaking at $37^{\circ} \mathrm{C}$. The measure of absorbance was carried out at different times of $0.5,1.0$, $2.0,3.0,4.0,5.0,6.0,12.0,24.0,48.0$, and $72.0 \mathrm{~h}$ using spectrophotometer (Shimadzu $1800 \mathrm{UV}$ ) at $\lambda \max =430 \mathrm{~nm}$.

The percentage of the release of Cur from Cur/GANPs into the media was calculated by:

$$
\begin{gathered}
\% \text { Release }=\frac{\text { Concentration of drug at tome } t}{\text { Concentration corresponding to }} \times 100 \\
100 \% \text { release of drug }
\end{gathered}
$$

The concentration that corresponded to $100 \%$ release of drug was calculated based on the absorbance measured after 7 days of the release of Cur from Cur/GANPs into the Phosphate buffer saline (PBS) at $\mathrm{pH} 7.4$ and $\mathrm{pH}$ 4.8. To 
compare the percentages of Cur released from GANPs with that from the physical mixture of Cur and GA, the same weight ratios as the GANPs were prepared to determine the release as described above. The release of active compounds was estimated as a percentage accordingly.

The behavior of Cur/GANPs at pH 7.4 and 4.8

Zeta potential and particle were measured to assess the deformation behavior and aggregation of nanoparticles at $\mathrm{pH} 7.4$ and 4.8 .

\section{The Scavenging Activity of Cur/GANPs with DPPH}

The DPPH scavenging test is based upon the reducing capacity of DPPH in the presence of antioxidant compounds by donating an electron or hydrogen to the free radicals indicated by the change of purple DPPH radicals into yellow stable compound (Sarika et al., 2015). Due to the potent antioxidant capacity of Trolox, it was used as a positive control in this assay. A serial dilution of $100 \mu \mathrm{g}$ of Trolox in $1 \mathrm{~mL}$ of methanol was used in the range of 50$200 \mu \mathrm{g} / \mathrm{mL}$. Two hundred microliters of DPPH solution were added to each well of the 96-well microplate. After shaking for $1 \mathrm{~min}$ and incubating the samples in a dark environment, the spectrophotometric light absorbance was measured at $517 \mathrm{~nm}$. The scavenging activity was calculated according to the following equation:

$\mathrm{DPPH}$ activity $(\%)=\left[1-\frac{A_{a}-A_{b}}{A_{c}}\right] \times 100$

where $A a, A b$, and $A c$ are the absorbance of samples, absorbance recorded without DPPH, and control absorbance, respectively.

\section{The Nitric-Oxide (NO) scavenging activity of Cur/GANPs}

The RAW 264.7 cells were cultured with a cell density of $1 \times$ 106 cells $/ 100 \mu \mathrm{L}$ of cell culture media in each well of the 96well plates for $24 \mathrm{~h}$. Then, free curcumin and Cur/GANPs were added with concentrations ranging between 15.6 and $500 \mu \mathrm{g} / \mathrm{mL}$. The cells were then challenged with $10 \mu \mathrm{g} / \mathrm{mL}$ of lipopolysaccharide (LPS) for $20 \mathrm{~h}$. The released Nitric oxide (NO) was indirectly quantified by measuring the quantity of nitrite released into the supernatant of macrophage cells. The nitrite quantification was determined by adding $100 \mu \mathrm{L}$ of Griess reagent to the medium of each well in the 96-well plate. The Griess reagent consists of $1 \%$ $(\mathrm{w} / \mathrm{v})$ sulfonamide and $0.1 \% \quad(\mathrm{w} / \mathrm{v}) \quad \mathrm{N}$-(1-naphtyl) ethylenediamine dihydrochloride. The microplate the reader was used to evaluate the absorbance at $540 \mathrm{~nm}$. A standard curve was plotted based on various concentrations of sodium nitrite to calculate the concertation of nitrite in the medium (Al-Qubaisi et al., 2013; Ranneh et al., 2016).

\section{$\beta$-carotene bleaching assay}

The assay is based on the oxidation of linoleic acid indicated by the decrease of the yellow color (bleaching) of $\beta$ carotene. This assay was implemented with some modification to the method previously described (Prieto et al., 2012). Briefly, the $\beta$-carotene solution was prepared after the dissolution of $2 \mathrm{mg}$ of $\beta$-carotene in $10 \mathrm{~mL}$ of chloroform then evaporated at $40^{\circ} \mathrm{C}$ under vacuum. After evaporation, Tween 80 (400 mg) and linoleic acid (40 mg) were mixed then added to $100 \mathrm{~mL}$ of distilled water. The mixture was vigorously shaken for $10 \mathrm{~min}$. An emulsion without $\beta$-carotene was prepared and used as blank. After adding free curcumin and Cur/GANPs at the specified concentrations $(50 \mu \mathrm{L})$ with $\beta$-carotene emulsion $(200 \mu \mathrm{L})$ into each well of the 96-well plate, the mixtures were incubated at $50^{\circ} \mathrm{C}$ in dark environment. At the end, $470 \mathrm{~nm}$ light absorbance was measured at $0 \mathrm{~min}$ and then at $20 \mathrm{~min}$ intervals for $100 \mathrm{~min}$. The antioxidant activity was evaluated as follows:

$A A_{0}=\left[1-\frac{\left(A_{0}-A_{t}\right)}{\left(A_{0 c}-A_{t c}\right)}\right] * 100$

where A0, At, A0c, and Atc, are the absorbance values of samples at $\mathrm{t}=0, \mathrm{t}=100 \mathrm{~min}$, and controls at $\mathrm{t}=0$ and $\mathrm{t}=$ $100 \mathrm{~min}$ respectively. Various concentrations of $\alpha$-tocopherol were used as standards.

\section{Antihypertensive activity}

This assay is based on the inhibition of Angiotensin converting enzyme (ACE) activity in vitro indicated by colorimetric evaluation of the conversion of hippurylhistidyl-leucine to hippuric acid in the presence of an inhibitor (Cur/GANPs). In this assay $100 \mu \mathrm{L}$ of Cur and Cur/GANPs were mixed with ACE $(25 \mu \mathrm{L}, \mathrm{pH} 8.3)$ at $37^{\circ} \mathrm{C}$. To assess the ACE inhibition activity, $10 \mu \mathrm{L}$ of hippurylhistidyl-leucine $(3.5 \mathrm{mM})$ was added to the mixture then incubated for 30,60 , and $90 \mathrm{~min}$. The reaction was stopped by adding $50 \mu \mathrm{L}$ of HCL $(1 \mathrm{M})$ to the solution followed by extraction of hippuric acid by Ethyl acetate $(1 \mathrm{~mL})$. After evaporation at $120^{\circ} \mathrm{C}$, the residue was re-dissolved in deionized water. Finally, the amount of hippuric acid was assessed by the measurement of absorbance at $228 \mathrm{~nm}$. The emulsion prepared without curcumin or Cur/GANPs was used as a control (Ahmad et al., 2017).

\section{Cell viability assay}

Four human cell lines, human colon cancer cells (HT29), human liver cancer (HepG2), and breast cancer (MDAMB231 and MCF7) cell lines were used in the cytotoxicity assay. Two hundred microliters of a $1 \times 10^{4}$ cells $/ \mathrm{mL}$ suspension were seeded into each well of the 96-well plate. After incubation for $24 \mathrm{~h}$, the media was aspirated, and the cells were treated with fresh media $(200 \mu \mathrm{L})$ including free curcumin and Cur/GANPs of various concentrations (15.6 to $100 \mu \mathrm{g} / \mathrm{mL}$ ). The plates were then incubated with the treatments for $72 \mathrm{~h}$ at $37^{\circ} \mathrm{C}$ with $5 \% \mathrm{CO}_{2}$. The cell viability was determined based on the MTT assay in which the media was removed, and the wells were washed three times using PBS to ensure that curcumin and Cur/ GANPs were removed. Then twenty microliters of MTT solution $(5 \mu \mathrm{g} / \mathrm{mL})$ were added into each well of the 96 -well with fresh media then mixed gently and incubated for 4 hours at $37^{\circ} \mathrm{C}$ with $5 \% \mathrm{CO}_{2}$. Then MTT-including culture medium was replaced by $200 \mu \mathrm{L} /$ well of DMSO to dissolve the formazan crystals. The absorbance was determined at $570 \mathrm{~nm}$ and the amount of drug required to inhibit $50 \%$ of cell growth (IC50) was calculated from the dose-response patterns from each cell line and compound (Al-Qubaisi et al., 2013). 


\section{Statistical Analysis}

The experiment was carried out in triplicates with multiple replicates. The data were used to calculate mean values and standard deviation. The comparison of the mean values was analyzed by the SPSS 16 for windows software. The difference of measurements was evaluated using one-way analysis of variance (ANOVA) and independent $t$-test with $p<0.05$ considered statistically significant.

\section{Results}

In the X-ray diffractogram of curcumin, sharp diffraction peaks were demonstrated at different diffraction angles $25.94^{\circ}, 27.96^{\circ}, 34.32^{\circ}$, and $37.82^{\circ}$ as observed in section $\mathrm{d}$ of Fig. 1. Sections $\mathrm{a}, \mathrm{b}$ and $\mathrm{c}$ demonstrate the diffractogram of

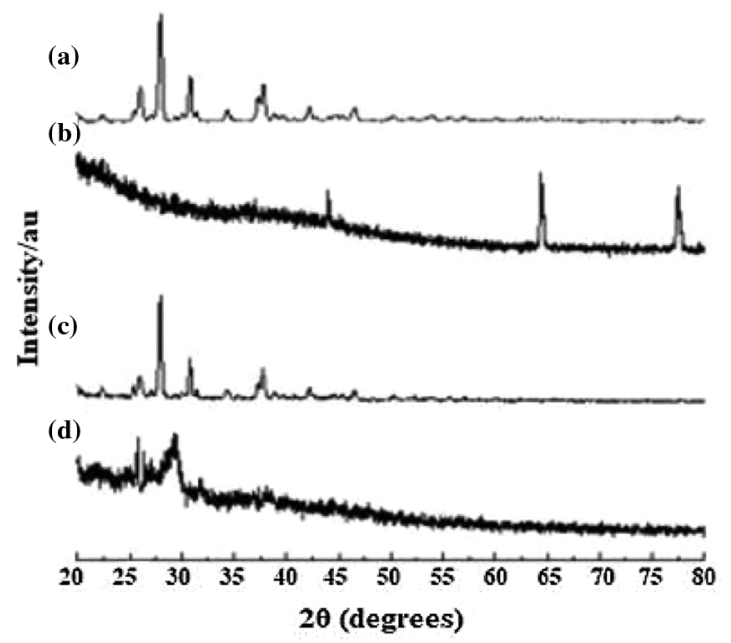

FIGURE 1. X-ray diffractogram: (a) curcumin, (b) GA, (c) physical mixture, (d) Cur/GANPs nanoparticles. (a) curcumin, (b) GA, (c) physical mixture of $\mathrm{Cu}$ and GA,

(d) Cur/GANPs nanoparticles.

Cur/GANPs have been formulated and the clear solution of Cur/GANPs displayed a particle size over the range of 20$260 \mathrm{~nm}$ (Polydispersity Index PDI $=0.32 \pm 0.13$ ), with the potential of $-24 \mathrm{mV}$ as displayed in Fig. 2a.

At freezing temperature of $-20^{\circ} \mathrm{C}$, the Cur/GANPs revealed a tendency to aggregate after melting that was confirmed by the reduction of the negative potential (Fig. 3A) and the increase of particle size of Cur/GANPs (Fig. 3B). The stability of the nanoparticle's formulation was also assessed in acidic and alkaline conditions as demonstrated (Fig. 4). aggregation and deformations were noticed in acidic $\mathrm{pH}$ as indicated with increased size and potential.

The in vitro drug release in the GANPs was calculated based on the curve of the UV-Vis spectrometer at $\lambda \max$, $430 \mathrm{~nm}$ for curcumin as shown there was a steady release of curcumin from the nanoparticle formulation over 2 days in acidic and alkaline $\mathrm{pH}$ (Fig. 5A). while the physical mixture had an immediate release pattern as observed in (Fig. 5B).

The Cur and Cur/GANPs scavenging of free radicals were evaluated using different in vitro assays including the DPPH, LPS stimulation, and the $\beta$-carotene bleaching assays. Trolox was utilized as a positive control due to its capacity to dissolve in the aqueous system and had shown a strong scavenging activity against DPPH. Upon the evaluation of curcumin and Cur/GANPs, both showed an antioxidant activity at the tested concentrations in the range $50-200 \mu \mathrm{g} / \mathrm{mL}$ as illustrated in Fig. 6. As demonstrated, the percentage of DPPH scavenging activities of Cur/GANPs was higher than free curcumin in each of the concentrations used $(p<0.05)$ as shown in Fig. 8.

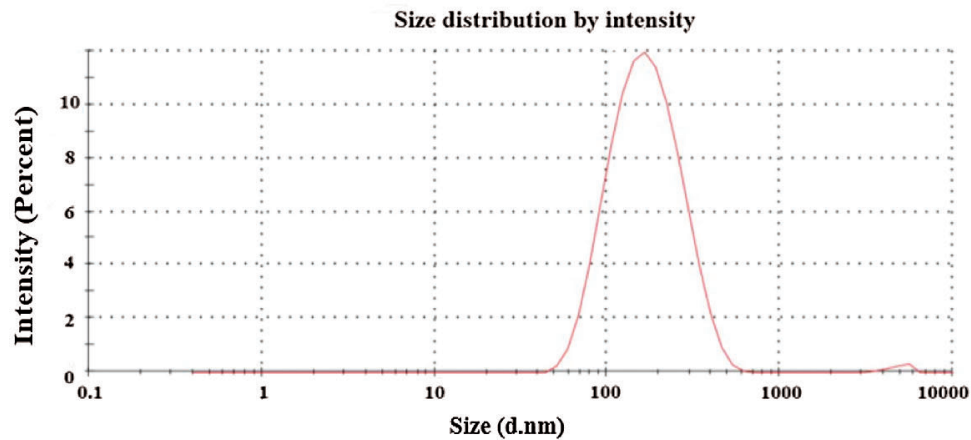

(a)

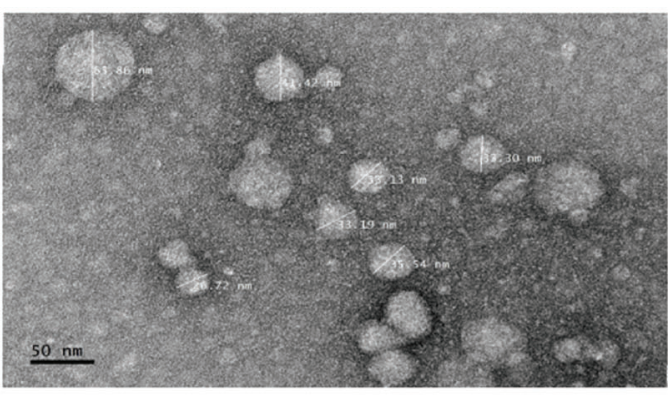

(b)

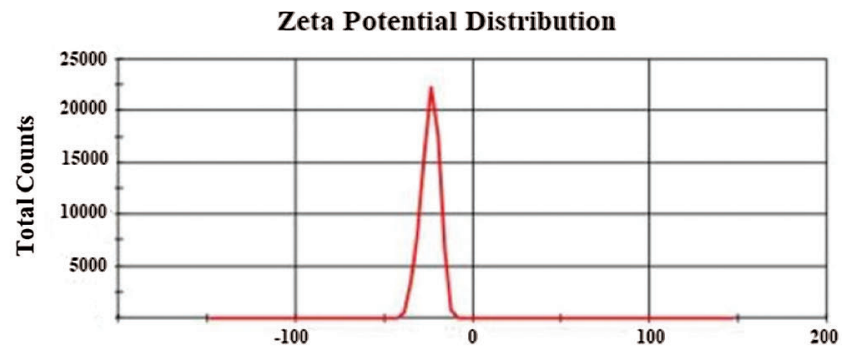

(c)

FIGURE 2. Estimation of Cur/GANPs size using Zeta sizer (a), Transmission electron microscope image of the developed NPs (b), and the Zeta potential (c) of Cur/GANPs. 

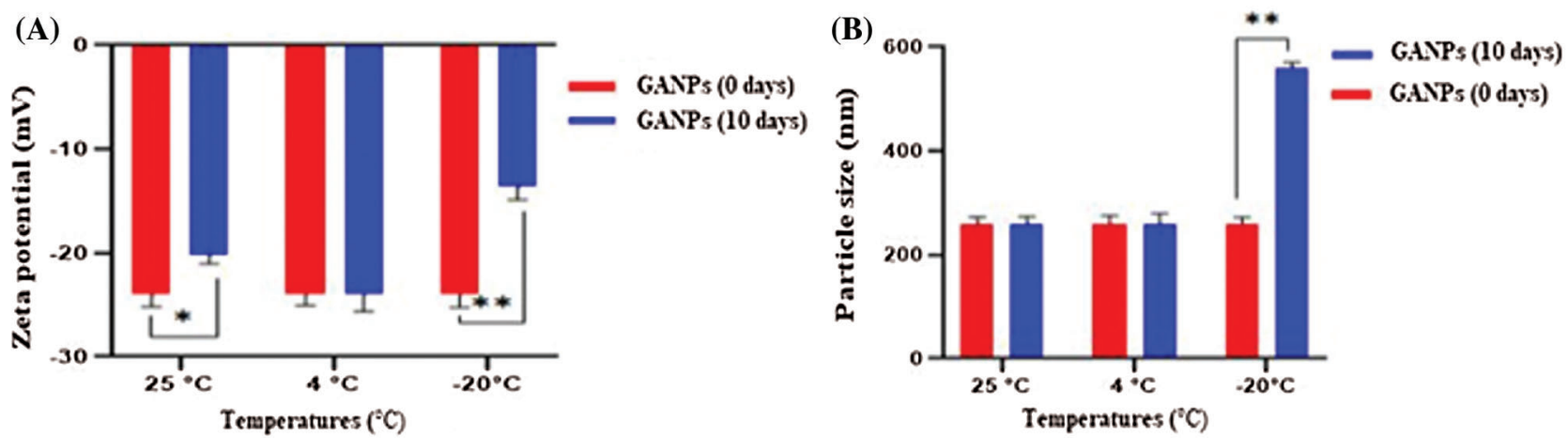

FIGURE 3. The stability of GANPs suspensions at three temperature settings of storage. The indicators of stability included (A) Zeta potential, and (B) Particle size. The data presented as Mean \pm SD of three experiments $(\mathrm{n}=3) .{ }^{\star} p<0.05,{ }^{\star *} p<0.01$.

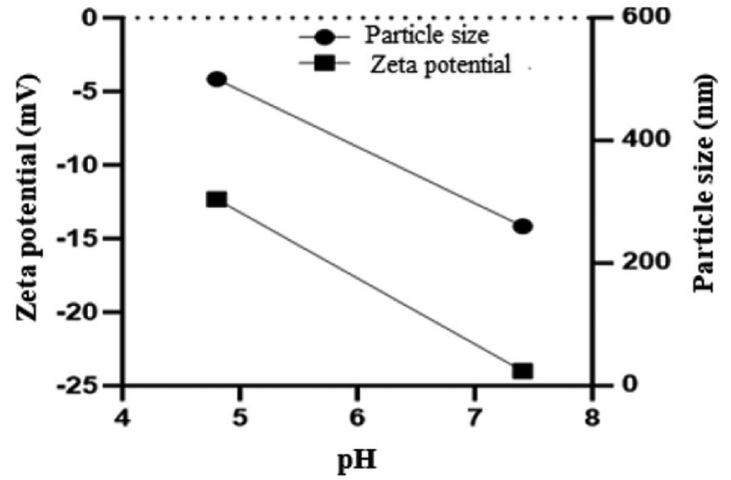

FIGURE 4. Aggregations and deformation of Cur/GANPs at $\mathrm{pH} 4.8$ and 7.4. Mean \pm SD of three experiments $(n=3)$.

Another assay was used to determine the antioxidant and anti-inflammatory properties of treatments known as the LPS stimulation test which was experimented with in the murine macrophage cell line (RAW 264.7). The murine macrophages treated with curcumin and Cur/GANPs revealed a considerable inhibition of NO production in their media as shown in Fig. 7A. When cells were pre-treated with curcumin or Cur/GANPs, LPS stimulation of nitrite oxide production was inhibited in a concentrationdependent manner. As shown, there was a significant increase in the viability of RAW 264.7 cells Fig. 7B. Cur/GANPs scavenging activity was twice higher than free curcumin at a concentration ranging from 31.5 to $500 \mu \mathrm{g} / \mathrm{mL}(p<0.05)$ as shown in.

The antioxidant activity of $\beta$-carotene increased in a dose-dependent manner with Cur/GANPs treatment as shown in Fig. 9. The highest antioxidant activity (70.11\%) was reported at $500 \mu \mathrm{g} / \mathrm{mL}$ concentration of Cur/GANPs that was significantly higher than the other concentrations $(p$-value $<0.05)$.

ACE inhibitors are medications prescribed to treat high blood pressure. In this study, the antihypertensive activity of Cur and Cur/GANPs was evaluated by converting hippurylhistidyl-leucine to hippuric acid (Hussein et al., 2012). Cur/GANPs exhibited a more potent inhibitory activity than the free curcumin $(p<0.05)$ suggesting a stronger antihypertensive activity as shown in Fig. 10.

In vitro cytotoxicity tests in cancer cells help as a preliminary screening tool of anticancer properties before more specific in vitro and in vivo assays are applied. The cytotoxic properties of curcumin in the free form and the nanoparticles formulation (Cur/GANPs) were assessed in different human cancer cell lines based on the reduction of MTT reagent by cancer cells as shown in Fig. 11. As shown,

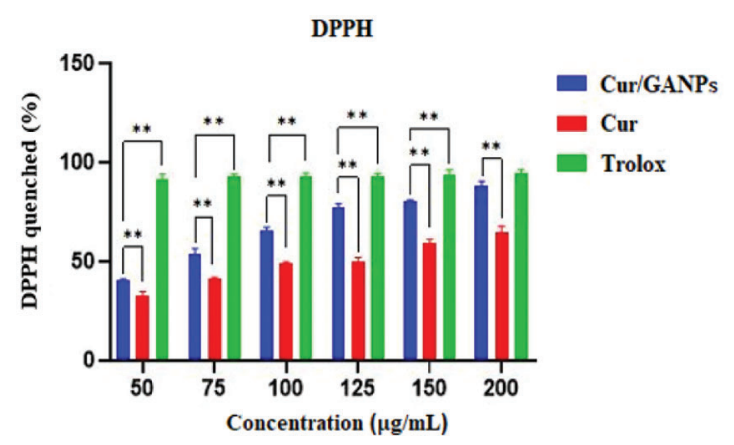

FIGURE 6. DPPH scavenging of free curcumin and Cur/GANPs. Independent $t$-test, Data shown are mean value $\pm \mathrm{SD}$, independent $t$-test, ${ }^{\star} p$-value $\leq 0.05,{ }^{* *} p$-value $\leq 0.01$.

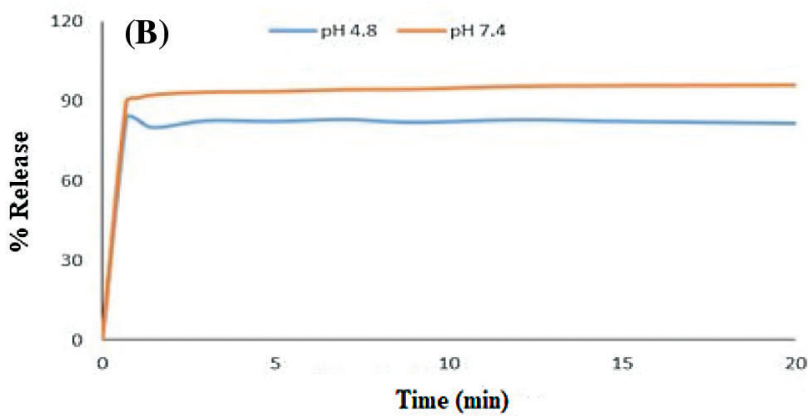

FIGURE 5. Release profiles of Cur from (A) GANPs, (B) physical mixture at $\mathrm{pH} 4.8$ and $\mathrm{pH} 7.4$. Mean \pm SD of three experiments $(\mathrm{n}=3$ ). 

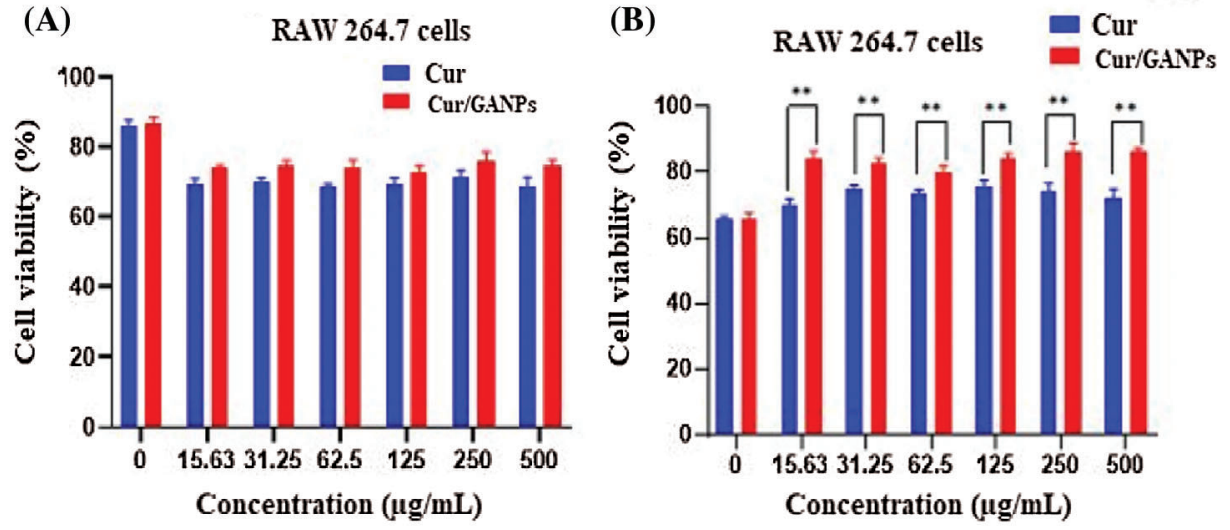

FIGURE 7. Cytotoxicity assay in RAW 264.7 cells treated with free curcumin and Cur/GANPs for $24 \mathrm{~h}$ at various concentrations without LPS stimulation (A) and with LPS stimulation (B); Independent $t$-test, Data shown are mean value $\pm \mathrm{SD}, * p$-value $\leq 0.05$, ${ }^{* *} p$-value $\leq 0.01$.

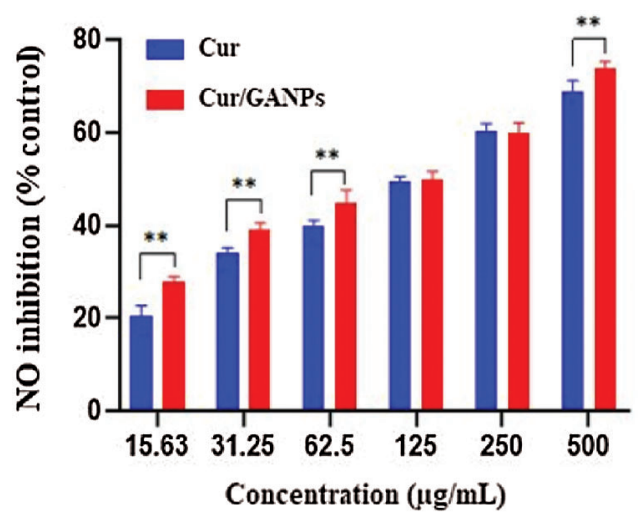

FIGURE 8. Nitric oxide radical scavenging activities of RAW 264.7 cells treated with different concentrations of free curcumin and Cur/ GANPs. Independent $t$-test, Data shown are mean value $\pm \mathrm{SD}$, independent $t$-test, ${ }^{\star} p$-value $\leq 0.05,{ }^{*} p$-value $\leq 0.01$.

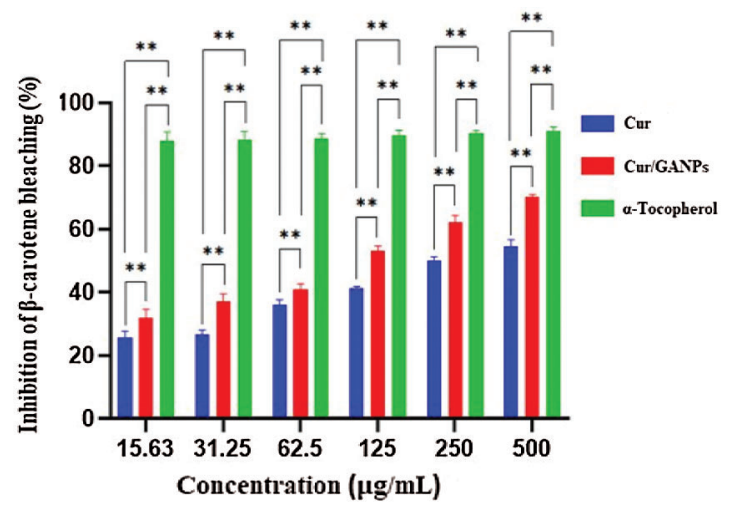

FIGURE 9. Inhibition (\%) of $\beta$-carotene bleaching with free curcumin and Cur/GANPS. Independent $t$-test, Data shown are mean value $\pm \mathrm{SD}$, independent $t$-test, ${ }^{*} p$-value $\leq 0.05,{ }^{* *} p$-value $\leq$ 0.01 .

there was a dose-dependent inhibition of cell viability with Cur/GANPs and the $\mathrm{IC}_{50}$ values of Cur/GANPs were significantly lower than free curcumin in all cancer cell types (HepG2, MCF-7, HT29, and MDA-MB231). indicating better therapeutic properties (Table 1).

\section{Discussion}

The freeze-drying method was selected in the preparation of the nanoparticles among the other methodologies due to its undemanding and eco-friendly characteristics. The

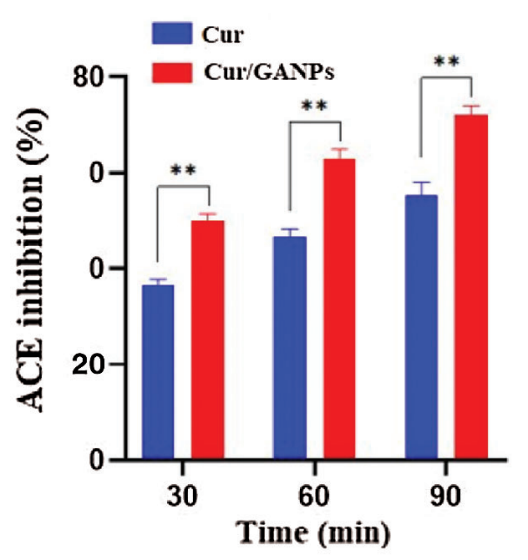

FIGURE 10. ACE inhibition (\%) for free curcumin and Cur/GANPs after 30,60, and 90 minutes. Independent $t$-test, Data shown are mean value $\pm \mathrm{SD}$, independent $t$-test, ${ }^{*} p$-value $\leq 0.05,{ }^{*} p$-value $\leq 0.01$.

produced freeze-dried powder was further reduced to ultrafine powder. The cryo-chemical method used in this study has provided several advantages compared with other conventional methods such as the small size of the end product and the greater purity and homogeneity.

The XRD diffractogram illustrated the crystalline nature of curcumin (Fig. 1). The same diffraction peaks appeared in the physical mixture pattern with a reduction of intensity. The GA polymer didn't show obvious peaks at $64.15^{\circ}$ and $77.35^{\circ}$ indicating the amorphous state of GA. Due to the interaction between curcumin and GA, Cur/GANPs did not exhibit the same diffraction peaks of free curcumin where the major peaks totally vanished. This suggests the conversion of curcumin from the crystalline state to the amorphous state. In the preparation of Cur/GANPs, the small size of the nanoparticles was due to the use of a highpressure homogenizer (Fig. 2). Due to its negative charge, Cur/GANPs are useful for the effective delivery of curcumin as therapeutic agents. TEM image is depicted in Fig. 2b showing the semi-spherical shape of individual particles.

It can be suggested that the aggregation of Cur/GANPs in $-20^{\circ} \mathrm{C}$ was due to the detachment of gum Arabic carriers from the nanoparticles prepared as showed by the decrease of zeta potential values. The detachments may be related to adjacent nanoparticles' interactions that cause the aggregation of Cur/GANPs suspensions. These findings are similar to previous studies, where larger particles are also produced by 


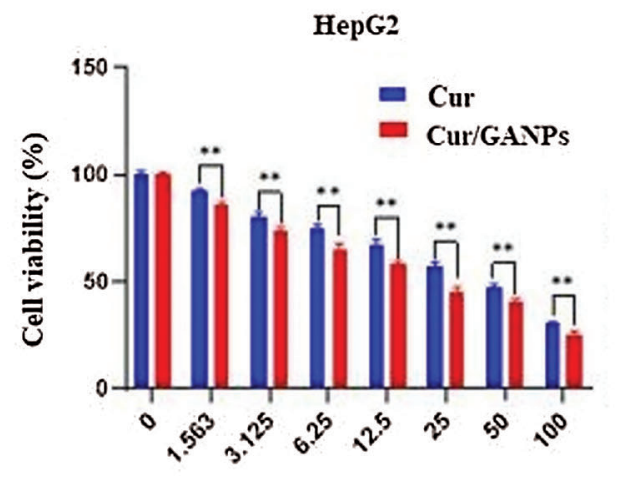

Concentration $(\mu \mathrm{g} / \mathrm{mL})$

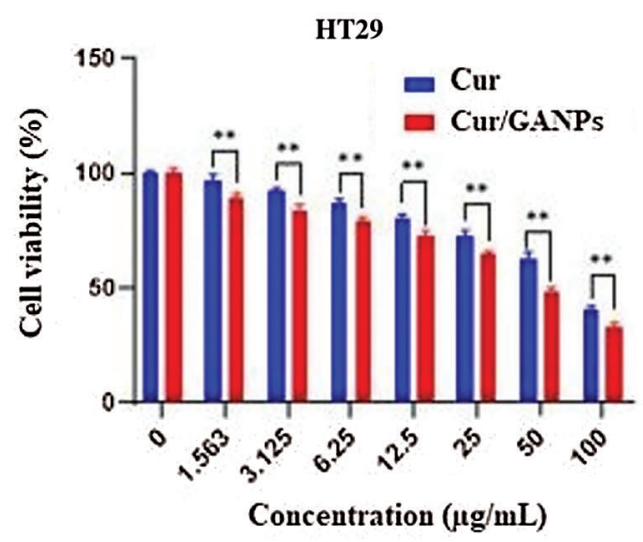

TABLE 1

$\mathrm{IC}_{50}$ of free curcumin, Cur/GANPs in HT29, MDA-MB231, MCF7, and HepG2 cell lines after $72 \mathrm{~h}$ of incubation. Each data represents the mean of three measurements \pm SD. $p<0.05$ is considered significant

\begin{tabular}{lllll}
\hline Treatment & \multicolumn{4}{c}{ IC $_{50}(\boldsymbol{\mu g} / \mathrm{mL})$} \\
\cline { 2 - 5 } & HT29 & MDA-MB231 & MCF7 & HepG2 \\
\hline Cu/GANPs & $20.14 \pm 1.3$ & $18.22 \pm 1.3$ & $16.1 \pm 1.01$ & $6.22 \pm 1.4$ \\
$\begin{array}{l}\text { Free } \\
\text { curcumin }\end{array}$ & $36.9 \pm 1.5$ & $33 . \pm 1.4$ & $30.1 \pm 1.1$ & $15.4 \pm 1.2$ \\
\hline
\end{tabular}

the rapid freezing process due to the electrostatic repulsive and stronger van der Waals attractive forces that occurred between nanoparticles (Albanese et al., 2012). Hence, the nanoparticles in powdered form are more stable than the preparation of suspensions. Also, the powdered nanoparticles improve the release of drugs in the dispersed phase with ease of storage during a long period. The use of cryoprotectant is recommended to decrease the risk of agglomeration of Cur/GANPs suspensions in temperature of storage of $\left(4^{\circ} \mathrm{C}\right)$ and usage within 10 days. As shown in Fig. 4, the Zeta potential of Cur/GANPs decreased with the reduction of $\mathrm{pH}$ from 7.4 to 4.8 , whereas the values of particle size of Cur/GANPs increased as the $\mathrm{pH}$ of solutions decreased to 4.8, mentioning the formation of larger particles due to the aggregation behavior caused by the weak electrostatic repulsion in the medium.

The release of Cur from GANPs was carried out using a phosphate buffer solution at $\mathrm{pH} 7.4$ and $\mathrm{pH}$ 4.8. Fig. 5
MCF7

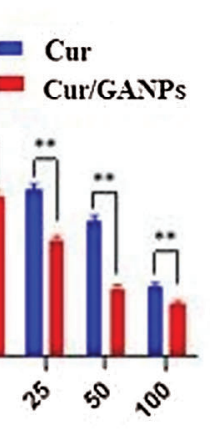

Concentration $(\mu \mathrm{g} / \mathrm{mL})$

MDA-MB231

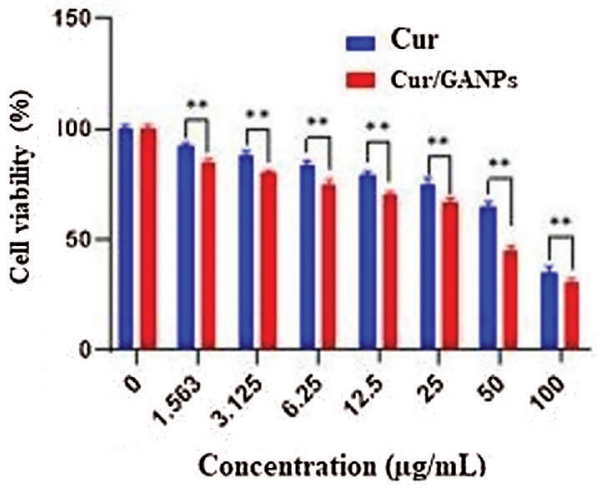

FIGURE 11. Cytotoxicity activity of curcumin, Cur/GANPs at different concentrations after $72 \mathrm{hrs}$ of treatment in four human cancer cell lines A: HepG2, B: MCF-7, C: HT29, and D: MDA-MB231). Data shown are mean value $\pm \mathrm{SD}$, independent $t$-test, ${ }^{\star} p$-value $\leq 0.05,{ }^{\star *} p$-value $\leq$ 0.01 .

exhibited that the release of Cur from GANPs at $\mathrm{pH} 4.8$ was divided into two phases based on the slope of release profiles and release percentages. An initial release burst was recorded for the first $1000 \mathrm{~min}$.

The rapid initial release of $\mathrm{Cur}$ at $\mathrm{pH} 7.4$ and $\mathrm{pH} 4.8$, respectively, was related to the weak absorption or bonding of the surface of Cur/GANPs. As shown in Fig. 5, curcumin was rapidly released from Cur/GANPs up to $65 \%$ and $33 \%$ at $\mathrm{pH} 4.8$ and $\mathrm{pH} 7.4$, respectively. A much slower release of Cur from Cur/GANPs in $\mathrm{pH} 7.4$ over a prolonged period of 3000 min than $\mathrm{pH} 4.8$.

The DPPH is characterized by its stability and its capacity to accept electrons or hydrogen radicals when it reacts with reducing agents to produce a diamagnetic hydrazine substance. In such a reaction the DPPH reagent losses it's color depending on the amount of reduction. Thus any substance capable of donating electrons or hydrogen atoms in the reaction will lead to the conversion of purple DPPH to the yellow 1, 1-diphenyl-2- picrylhydrazine, a reaction that can be evaluated by measuring color intensity using the spectrophotometer with absorbance at $517 \mathrm{~nm}$. As shown in Fig. 6, the Cur/GANPs had a higher percentage of antioxidant capacity than the pure curcumin which can be attributed to the reactivity of functional groups of gum Arabic. Antioxidant properties of gum Arabic (GA) has been established previously which confirms its biomedical applications as a nanocarrier for tumor-specific treatment (Gamal et al., 2003).

Nitric oxide (NO) is an endogenous radical that is involved in regulating essential biological functions such as neurotransmission, controlling the vascular caliber, and blood flow. However, NO is also involved with pathological 
events due to its contribution to oxidative damage. Nitric oxide (NO) plays a major role in inducing oxidative stress in several inflammatory processes. One of the reactive free radicals that is produced by the $\mathrm{NO}$ reaction with superoxide radical is peroxynitrite anion $\left(\mathrm{ONOOO}^{-}\right)$which is a strong oxidant capable of interacting with organic molecules like lipids inducing the aberrant inflammatory responses (Mikkelsen and Wardman, 2003). The test aimed to determine the nitric oxide (NO) scavenging activity of the developed formulation upon stimulation of the macrophages with bacterial lipopolysaccharide (LPS). In this experiment, nitric oxide radicals are generated from sodium nitroprusside by the macrophages nitric oxide synthase enzyme that contributes with other immune mediators in the inflammatory responses (Dowding et al., 2012). Then the released NO radicals interacts with oxygen to produce nitrite ions in an aqueous solution at neutral $\mathrm{pH}$ which is measured by using the Griess reaction reagent. In the beginning, the potential toxicity of the macrophages in response to LPS stimulation was determined following treatment with curcumin and Cur/GANPs using the MTT assay. The same experiment setting was also repeated without LPS stimulation. As shown in Fig. 7a, the treatments had a minimal influence on the viability of RAW 264.7 cells until $500 \mu \mathrm{g} / \mathrm{mL}$ concentration. Furthermore, upon stimulation with LPS, the viability of the cells was less compared to the cells without stimulation; however, with Cur/GANPs nanoparticles treatment, the viability of the cells had significantly improved as shown in Fig. 7b. The results confirmed that both curcumin and Cur/GANPs had a minimal toxic effect on the murine macrophages with significantly less toxicity for the nanoformulation. This may be due to the biocompatibility of the carrier (GA) which was also demonstrated in other reports confirming that GA formulations had low toxicity in biological cells (Kong et al., 2014).

The mechanism of NO inhibition by curcumin and Cur/ GANPs was not clarified in this study. In other reports, curcumin had also shown inhibitory activity on NO and other mediators of inflammation by inhibition of cyclooxygenase, nitric oxide synthase, lipoxygenase enzymes, and NF kappa B (Bhaumik et al., 2000; Bengmark, 2006).

The main concern in the determination of the antioxidant effects of different agents is due to their potential roles in protecting the biological system from the deleterious consequences of oxidizing agents including hydrogen peroxides and hydroxyl radicals (Castro et al., 2006). Like many extracts of traditional medicines, the therapeutic effects of Cur/GANPs may be attributed to its activity in scavenging free radicals. The reported therapeutic properties of curcumin were attributed to its activity in scavenging reactive oxygen species (Deguchi, 2015). The study demonstrated the potent antioxidant and antiinflammatory properties of curcumin that were preserved and enhanced in the nanoformulation. This finding is consistent with other studies that confirmed GA's ability to preserve and enhance the antioxidant properties of phenolic compounds in various formulations (Pitalua et al., 2010; Ahmed et al., 2016). The enhanced antioxidant activity may be attributed to the antioxidant properties of GA that added a synergistic effect in the formulation. Gum Arabic had shown protective properties against the attacks of lipoxygenase and free radicals (GarcíaMartínez et al., 2018). In addition, GA had shown in studies its targeting specificity based on the interaction of hydroxyl groups with asialoglycoprotein receptors. Thus, this polymer has excellent potential for delivering bioactive agents as a target-oriented delivery system, functioning through receptormediated endocytosis (Gamal-Eldeen et al., 2016).

The $\beta$-carotene bleaching assay had been used to confirm the antioxidant properties of the NPs treatment. This assay depends on the oxidation of $\beta$-carotene by linoleic acid in the emulsion system causing rapid discoloration due to the formation of linoleate free radicals. Agents with the antioxidant effect would deter these changes and are measures using color changes.

$\beta$-carotene is a natural carotenoid derived from plants deemed as a major precursor of vitamin A. It functions as a free radical scavenger that protected the human body against the attack of free radicals (Yusuf et al., 2012). $\beta$-carotene is also reported to protect the nervous system from neurodegenerative disorders that are largely attributed to oxidative stress (Obulesu and Bramhachari, 2011). The principle of the $\beta$-carotene assay is based on linoleic acid oxidation, which resulted in a decrease of $\beta$-carotene's yellow color. This assay added another evidence to support the antioxidant potential of curcumin in the free and nanoparticle form that was demonstrated at various concentrations in comparison with $a$-tocopherol as shown in Fig. 9. The results showed that both curcumin and Cur/GANPs could inhibit ACE. In Fig. 10, after 90 min of incubation, $100 \mu \mathrm{L}$ of $5 \mu \mathrm{g} / \mathrm{mL}$ of Cur/GANPs and free curcumin inhibited ACE with a maximal percentage of $72.3 \%$ and $55.4 \%$, respectively.

The demonstrated antihypertensive effect of curcumin was consistent with findings in other studies; in which it had similar ACE inhibitory effects to the classical ACE inhibitor class of medications (Anand et al., 2007; Rachmawati et al., 2016; Shome et al., 2016). The angiotensin-converting-enzyme is one of the main regulatory elements in the cardiovascular system with therapeutic potentials being the target of several treatments. The ACE enzyme is a zinc metalloprotease a carboxypeptidase or dipeptidyl carboxypeptidase (EC 3.4.15.1) that is uniformly found in mammalian tissues with the main function of converting angiotensin $\mathrm{I}$ to the potent vasoconstrictor angiotensin II (Sarmadi et al., 2011). In this assay, the percentage inhibition of curcumin and Cur/GANPs was proportional to the decrease of absorbance measurements at $228 \mathrm{~nm}$. Cur/GANPs had more potent ACE inhibitory effects compared to free curcumin, which may be attributed to the increase in bioavailability of curcumin and the synergistic properties of gum Arabic coating (Hassani et al., 2019; Jaafar, 2019). Therefore, it can be suggested that encapsulation of curcumin in gum Arabic could improve the antihypertensive capacity of curcumin and such a complexation of gum Arabic with curcumin may represent an important alternative antihypertensive treatment.

Apparently, free curcumin and Cur/GANPs had similar cytotoxicity in the cancer cell lines after $72 \mathrm{~h}$ of incubation. Such cytotoxic effects of curcumin were reported using nanoformulation in colon cancer cells in vitro without reporting the mechanism (Prajakta et al., 2009; Selvam et al., 2019). The 
stipulated mechanism of curcumin anticancer properties was attributed in several studies to NF-kB, an important transcription factor in the oncogenic signaling pathways in ovarian cancer cells in vitro and in vivo (Lin et al., 2007), breast cancer cells (Chung and Vadgama, 2015). Although, other reports demonstrated curcumin anticancer properties that were attributed to interference with cell cycle, apoptosis and proliferation markers through modulation of cancer-specific micro RNAs in lung cancer (Lelli et al., 2017) and pancreatic cancer cells (Nagaraju et al., 2019).

Furthermore, the liver cancer cells (HepG2) were more sensitive to both treatments compared to other cancer cell lines with $50 \%$ of the cells inhibited $\left(\mathrm{IC}_{50}\right)$ by concentrations of 15.4 and 6.22 for curcumin and Cur/ GANPs respectively (Table 1 ). This finding is consistent with a study conducted on HepG2 cells using free curcumin where significant inhibition of cell proliferation was detected and attributed to cell cycle and cytoskeletal interference (Jiang et al., 2013). In this study, the cytotoxicity was significantly improved by the nanoformulation in which the anticancer activity of curcumin nanoparticles (Cur/GANPs) was two times higher than free curcumin. This may be attributed to the size of the delivered particles (Bioavailability) and the enhanced cellular uptake. In fact, some evidence pointed to the specific binding of the galactose groups of GA coating material with asialoglycoprotein receptors on the hepatocytes enhancing the cellular receptor-mediated endocytosis of curcumin (Sarika et al., 2015). That specific binding enhanced the cytotoxicity in HepG2 cells compared with MCF- 7 cells and such binding could partly explain the finding in this study. In addition to the unique properties of GA, particularly high stability and low toxicity.

\section{Conclusion}

Nano formulation of curcumin using Gum Arabic significantly enhances the antineoplastic properties of free curcumin. This adds further evidence to the therapeutic properties of curcumin in diseases like cancer and cardiovascular diseases due to its potency and lower toxicity compared with other chemotherapeutic agents. The effects are mainly attributed to the antioxidant properties that were further enhanced with Gum Arabic. These observations demand further investigations to uncover the underlying mechanisms and effects on the survival mechanisms of cancer cells such as invasion, metastasis, apoptosis, and other processes using in vitro and in vivo settings.

Author Contributions: The authors confirm contribution to the paper as follows: study conception and design: Wisam Nabeel Ibrahim, and Abd Almonem Doolaanea; data collection: Abdelkader Hassani; analysis and interpretation of results: Abdelkader Hassani, Wisam Nabeel Ibrahim, Aslina Hussain, Mothanna Sadiq Al-Qubaisi, Mohamed Lakhder Belfar, Hakim Belkhalfa, Hamid Hammad Enezei, Hamid Zentou; draft manuscript preparation: Abdelkader Hassani, Wisam Nabeel Ibrahim and Abd Almonem Doolaanea. All authors reviewed the results and approved the final version of the manuscript.
Availability of Data and Materials: The datasets generated during and/or analyzed during the current study are available from the corresponding author on reasonable request.

Funding Statement: This study was supported by the Malaysian Ministry of Higher Education Fundamental Research Grant Scheme (FRGS17-005-0571), Prototype Research Grant Scheme (PRGS19-005-0049), and Ministry of Science, Technology, and Innovation (MOSTI) Grant No. SMF18-001-0001.

Conflicts of Interest: The authors declare that they have no conflicts of interest to report regarding the present study.

\section{References}

Abdelwahed WG, Degobert S, Stainmesse H, Fessi H (2006). Freezedrying of nanoparticles: Formulation, process and storage considerations. Advanced Drug Delivery Reviews 58: 16881713. DOI 10.1016/j.addr.2006.09.017.

Ahmad I, Yanuar A, Mulia K, Mun'im A (2017). Review of angiotensin-converting enzyme inhibitory assay: Rapid method in drug discovery of herbal plants. Pharmacognosy Reviews 11: 1-7. DOI 10.4103/phrev.phrev_45_16.

Ahmed AA, Fedail SJ, Musa HH, Musa TH, Sifaldin AZ (2016). Gum Arabic supplementation improved antioxidant status and alters expression of oxidative stress gene in ovary of mice fed high fat diet. Middle East Fertility Society Journal 21: 101-108. DOI 10.1016/j.mefs.2015.10.001.

Albanese A, Peter S, Warren CW (2012). The effect of nanoparticle size, shape, and surface chemistry on biological systems. Annual Review of Biomedical Engineering 14: 1-16. DOI 10.1146/annurev-bioeng-071811-150124.

Al-Mosawi AJ (2002). The challenge of chronic renal failure in the developing world: Possible use of acacia gum. Pediatric Nephrology 17: 390-391. DOI 10.1007/s00467-001-0755-4.

Al-Qubaisi MS, Rasedee MH, Flaifel SH, Ahmad S, Hussein-Al-Ali MZ et al. (2013). Cytotoxicity of nickel zinc ferrite nanoparticles on cancer cells of epithelial origin. International Journal of Nanomedicine 8: 2497-2508. DOI 10.2147/IJN.S42367.

Amalraj AA, Pius S, Gopi S, Gopi S (2017). Biological activities of curcuminoids, other biomolecules from turmeric and their derivatives-A review. Journal of Traditional and Complementary Medicine 7: 205-233. DOI 10.1016/j. jtcme.2016.05.005.

Anand P, Kunnumakkara BA, Newman AB, Aggarwal BB (2007). Bioavailability of curcumin: Problems and promises. Molecular Pharmaceutics 4: 807-818. DOI 10.1021/mp700113r.

Ardakani TSA, Meidanchi AS, Shakeri-Zadeh A (2020). $\mathrm{Fe}_{3} \mathrm{O}_{4} @ \mathrm{Au} /$ reduced graphene oxide nanostructures: Combinatorial effects of radiotherapy and photothermal therapy on oral squamous carcinoma $\mathrm{KB}$ cell line. Ceramics International 46: 28676-28685. DOI 10.1016/j.ceramint.2020.08.027.

Bae IY, Oh IK, Jung DS, Lee HG (2019). Influence of arabic gum on in vitro starch digestibility and noodle-making quality of Segoami. International Journal of Biological Macromolecules 125: 668-673. DOI 10.1016/j.ijbiomac.2018.12.027.

Bengmark S (2006). Curcumin, an atoxic antioxidant and natural NFkappaB, cyclooxygenase-2, lipooxygenase, and inducible nitric oxide synthase inhibitor: A shield against acute and chronic diseases. Journal of Parenteral and Enteral Nutrition 30: 45-51. DOI 10.1177/ 014860710603000145. 
Bhaumik S, Jyothi MD, Khar A (2000). Differential modulation of nitric oxide production by curcumin in host macrophages and NK cells. FEBS Letters 483: 78-82. DOI 10.1016/ S0014-5793(00)02089-5.

Butstraen C, Salaün F (2014). Preparation of microcapsules by complex coacervation of gum Arabic and chitosan. Carbohydrates Polymers 99: 608-616. DOI 10.1016/j.carbpol.2013.09.006.

Castro IA, Rogero MM, Junqueira RM, Carrapeiro MM (2006). Free radical scavenger and antioxidant capacity correlation of alpha-tocopherol and Trolox measured by three in vitro methodologies. International Journal of Food Sciences and Nutrition 57: 75-82. DOI 10.1080/09637480600656199.

Chidambaram M, Krishnasamy K (2014). Drug-Drug/DrugExcipient compatibility studies on curcumin using nonthermal methods. Advanced Pharmaceutical Bulletin 4: 309-312. DOI 10.5681/apb.2014.045.

Chung SS, Vadgama JV (2015). Curcumin and epigallocatechin gallate inhibit the cancer stem cell phenotype via downregulation of STAT3-NFkB signaling. Anticancer Research 35: $39-46$

Deguchi A (2015). Curcumin targets in inflammation and cancer. Endocrine, Metabolic \& Immune Disorders-Drug Targets 15: 88-96. DOI 10.2174/1871530315666150316120458.

Dowding JM, Dosani T, Kumar A, Seal S, Self TW (2012). Cerium oxide nanoparticles scavenge nitric oxide radical ( $\mathrm{NO}$ ). Chemical Communications 48: 4896-4898. DOI 10.1039/ c2cc30485f.

Fadus MC, Lau C, Bikhchandani J, Lynch TH (2017). Curcumin: An age-old anti-inflammatory and anti-neoplastic agent. Journal of Traditional and Complementary Medicine 7: 339-346. DOI 10.1016/j.jtcme.2016.08.002.

Gamal A, Mostafa M, Al-shabanah OA, Al-bekairi AM, Nagi MN (2003). Protective effect of arabic gum against acetaminophen-induced hepatotoxicity in mice. Pharmacological Research 48: 631-635. DOI 10.1016/S1043-6618(03)00226-3.

Gamal-Eldeen AD, Moustafa SM, El-Daly EA, El-Hussieny S, Saleh $\mathrm{M}$ et al. (2016). Photothermal therapy mediated by gum Arabic-conjugated gold nanoparticles suppresses liver preneoplastic lesions in mice. Journal of Photochemistry and Photobiology B: Biology 163: 47-56. DOI 10.1016/j. jphotobiol.2016.08.009.

Gangwar RK, Tomar GB, Dhumale VA, Zinjarde S, Sharma RB et al. (2013). Curcumin conjugated silica nanoparticles for improving bioavailability and its anticancer applications. Journal of Agricultural and Food Chemistry 41: 130926133947000. DOI 10.1021/jf402894x.

García-Martínez E, Andújar A, Yuste Del C, Prohens J, MartínezNavarrete N (2018). Antioxidant and anti-inflammatory activities of freeze-dried grapefruit phenolics as affected by gum arabic and bamboo fibre addition and microwave pretreatment. Journal of the Science Food and Agriculture 98: 3076-3083.

Gupta AS, Mahajan R, Sharma R (2015). Evaluation of antimicrobial activity of Curcuma longa rhizome extract against Staphylococcus aureus. Biotechnology Reports 6: 51-55. DOI 10.1016/j.btre.2015.02.001.

Hanahan D, Weinberg RA (2011). Hallmarks of cancer: The next generation. Cell 144: 646-674. DOI 10.1016/j.cell.2011.02.013.

Hassani A, Hussain SA, Abdullah N, Kamarudin S, Rosli R (2019). Antioxidant Potential and Angiotensin-Converting Enzyme (ACE) inhibitory activity of orotic acid-loaded gum arabic nanoparticles. AAPS PharmSciTech 20: 244. DOI 10.1208/ s12249-018-1238-2.
Hassani A, Mahmood S, Enezei HH, Hussain SA, Hamad HA et al. (2020). Formulation, characterization and biological activity screening of sodium alginate-gum arabic nanoparticles loaded with curcumin. Molecules 25: 2244. DOI 10.3390/ molecules25092244.

Hussein Al Ali SH, Al-Qubaisi M, Hussein MZ, Ismail M, Zainal Z et al. (2012). Controlled release and angiotensin-converting enzyme inhibition properties of an antihypertensive drug based on a perindopril erbumine-layered double hydroxide nanocomposite. International Journal of Nanomedicine 7: 2129-2141. DOI 10.2147/IJN.

Ibrahim WN, Rosli LM, Doolaanea AA (2020). Formulation, cellular uptake and cytotoxicity of thymoquinone-loaded PLGA nanoparticles in malignant melanoma cancer cells. International Journal of Nanomedicine 15: 8059-8074. DOI 10.2147/IJN.S269340.

Jaafar NS (2019). Clinical effects of Arabic gum (Acacia): A mini review. Iraqi Journal of Pharmaceutical Sciences 28: 9-16. DOI 10.31351/vol28iss2pp9-16.

Jafarzadeha N, Nadafanb M, Malekfarc R, Shakeri-Zadehd A, Meidanchie A et al. (2019). Structural, optical and dielectric studies of Ag nanoparticles decorated by herceptin. Physica E: Low-dimensional Systems and Nanostructures 114: 113562. DOI 10.1016/j.physe.2019.113562.

Jiang JH, Jin L, Liu J, Pi FY, Cai J (2013). Curcumin disturbed cellcycle distribution of HepG2 cells via cytoskeletal arrangement. Scanning 35: 253-260. DOI 10.1002/sca.21058.

Kong H, Yang J, Zhang Y, Fang YK, Phillips GO (2014). Synthesis and antioxidant properties of gum arabic-stabilized selenium nanoparticles. International Journal of Biological Macromolecules 65: 155-162. DOI 10.1016/j.ijbiomac.2014.01.011.

Lelli D, Pedone C, Majeed M, Sahebkar A (2017). Curcumin and lung cancer: The role of microRNAs. Current Pharmaceutical Design 23: 3440-3444. DOI 10.2174/ 1381612823666170109144818.

Lin YG, Kunnumakkara AB, Nair A, Merritt WM, Han LY et al. (2007). Curcumin inhibits tumor growth and angiogenesis in ovarian carcinoma by targeting the nuclear factorkappaB pathway. Clinical Cancer Research 13: 3423-3430. DOI 10.1158/1078-0432.CCR-06-3072.

Majumder PS, Bhunia JB, Chaudhuri A (2014). Inhibiting tumor growth by targeting liposomally encapsulated CDC20siRNA to tumor vasculature: Therapeutic RNA interference. Journal of Controlled Release 180: 100-108. DOI 10.1016/j. jconrel.2014.02.012.

Meidanchi A (2020a). Mg (1-x) $\mathrm{CuxFe}_{2} \mathrm{O}_{4}$ superparamagnetic nanoparticles as nano-radiosensitizer agents in radiotherapy of MCF-7 human breast cancer cells. Nanotechnology 31: 325706. DOI 10.1088/1361-6528/ab8cf2.

Meidanchi A (2020b). Cobalt ferrite nanoparticles supported on reduced graphene oxide sheets: Optical, magnetic and magneto-antibacterial studies. Nanotechnology 31: 1-10.

Meidanchi A, Motamed A (2020). Preparation, characterization and in vitro evaluation of magnesium ferrite superparamagnetic nanoparticles as a novel radiosensitizer of breast cancer cells. Ceramics International 46: 17577-17583. DOI 10.1016/j. ceramint.2020.04.057.

Meidanchi A, Ansari H (2020). Copper spinel ferrite superparamagnetic nanoparticles as a novel radiotherapy enhancer effect in cancer treatment. Journal of Cluster Science 32: 657-663. DOI 10.1007/s10876-020-01832-5.

Meiyanto ED, Putri RA, Susidarti RM, Sardjiman A, Fitriasari UH et al. (2014). Curcumin and its analogues (PGV-0 and 
PGV-1) enhance sensitivity of resistant MCF-7 cells to doxorubicin through inhibition of HER2 and NF-kB activation. Asian Pacific Journal of Cancer Prevention 15: 179-184. DOI 10.7314/APJCP.2014.15.1.179.

Mikkelsen RB, Wardman P (2003). Biological chemistry of reactive oxygen and nitrogen and radiation-induced signal transduction mechanisms. Oncogene 22: 5734-5754. DOI 10.1038/sj.onc.1206663.

Mondal GS, Barui SS, Chaudhuri A (2013). Tumor growth inhibition through targeting liposomally bound curcumin to tumor vasculature. Journal of Controlled Release 172: 832-840. DOI 10.1016/j.jconrel.2013.08.302.

Nagaraju GPL, Benton SR, Bethi MS, El-Rayes BF (2019). Curcumin analogs: Their roles in pancreatic cancer growth and metastasis. International Journal of Cancer 145: 10-19. DOI 10.1002/ijc.31867.

Notarbartolo MP, Poma D, Perri L, Dusonchet MC, D'Alessandro N (2005). Antitumor effects of curcumin, alone or in combination with cisplatin or doxorubicin, on human hepatic cancer cells. Analysis of their possible relationship to changes in NF-kB activation levels and in IAP gene expression. Cancer Letters 224: 53-65. DOI 10.1016/j.canlet.2004.10.051.

Obulesu MM, Bramhachari DPV (2011). Carotenoids and Alzheimer's disease: an insight into therapeutic role of retinoids in animal models. Neurochemistry International 59: 535-541. DOI 10.1016/j.neuint.2011.04.004.

Pieczykolan E, Kurek MA (2019). Use of guar gum, gum arabic, pectin, beta-glucan and inulin for microencapsulation of anthocyanins from chokeberry. International Journal of Biological Macromolecules 129: 665-671. DOI 10.1016/j. ijbiomac.2019.02.073.

Pitalua E, Jimenez ME, Beristain VC (2010). Antioxidative activity of microcapsules with beetroot juice using gum Arabic as wall material. Food and Bioproducts Processing 88: 253-258. DOI 10.1016/j.fbp.2010.01.002.

Prajakta DJ, Ratnesh K, Chandan S, Suresh SG, Vandana PV (2009). Curcumin loaded $\mathrm{pH}$-sensitive nanoparticles for the treatment of colon cancer. Journal of Biomedical Nanotechnology 5: 445-455. DOI 10.1166/jbn.2009.1038.

Prasad SS, Tyagi GAK (2017). Reactive oxygen species (ROS) and cancer: Role of antioxidative nutraceuticals. Cancer Letters 387: 95-105. DOI 10.1016/j.canlet.2016.03.042.

Prieto MA, Rodríguez-Amado I, Vázquez JA, Murado MA (2012). $\beta$ Carotene assay revisited. application to characterize and quantify antioxidant and prooxidant activities in a microplate. Journal of Agricultural and Food Chemistry 60: 8983-8993. DOI 10.1021/jf302218g.

Rachmawati HIS, Soraya NF, Rahma KA (2016). In vitro study on antihypertensive and antihypercholesterolemic effects of a curcumin nanoemulsion. Scientia Pharmaceutica 84: 131140. DOI 10.3797/scipharm.ISP.2015.05.
Raikos VA, McDonagh V, Ranawana GJ, Wellness DH (2016). Processed beetroot (Beta vulgaris L.) as a natural antioxidant in mayonnaise: Effects on physical stability, texture and sensory attributes. Food Science and Human Wellness 5: 191-198. DOI 10.1016/j.fshw.2016.10.002.

Ranneh Y, Ali F, Al-Qubaisi M, Ismail AEM (2016). The inhibitory activity of cocoa phenolic extract against pro-inflammatory mediators secretion induced by lipopolysaccharide in RAW 264.7 cells. SpringerPlus 5: 95. DOI 10.1186/s40064-0162138-0.

Reckziegel PVT, Dias DM, Benvegnú N, Boufleur RCS, Barcelos HJ et al. (2016). Antioxidant protection of gallic acid against toxicity induced by $\mathrm{Pb}$ in blood, liver and kidney of rats. Toxicology Reports 3: 351-356. DOI $10.1016 / \mathrm{j}$. toxrep.2016.02.005.

Sarika PR, James PR, Kumar DK, Kumary RTV (2015). Gum arabiccurcumin conjugate micelles with enhanced loading for curcumin delivery to hepatocarcinoma cells. Carbohydrates Polymers 134: 167-174. DOI 10.1016/j.carbpol.2015.07.068.

Sarika PRK, Cinthya A, Jayakrishnan PR, James ANR (2014). Modified gum arabic cross-linked gelatin scaffold for biomedical applications. Materials Science and Engineering: C 43: 272-279. DOI 10.1016/j.msec.2014.06.042.

Sarmadi B, Ismail A, Hamid M (2011). Antioxidant and angiotensin converting enzyme (ACE) inhibitory activities of cocoa (Theobroma cacao L.) autolysates. Food Research International 44: 290-296. DOI 10.1016/j.foodres.2010.10.017.

Selvam CS, Prabu L, Jordan BC, Purushothaman Y, Umamaheswari MS et al. (2019). Molecular mechanisms of curcumin and its analogs in colon cancer prevention and treatment. Life Sciences 239: 117032. DOI 10.1016/j.lfs.2019.117032.

Shome SA, Talukdar MD, Choudhury MK, Upadhyaya HB (2016). Curcumin as potential therapeutic natural product: A nanobiotechnological perspective. Journal of Pharmacy and Pharmacology 68: 1481-1500. DOI 10.1111/jphp.12611.

Wang QX, Zhuang J, Mu ZB, Deng H, Jiang L et al. (2013). Delivery of therapeutic agents by nanoparticles made of grapefruitderived lipids. Nature Communications 4: 269. DOI 10.1038/ncomms2886.

Wu CC, Chen GB (2010). Facile green synthesis of gold nanoparticles with gum arabic as a stabilizing agent and reducing agent. Gold Bulletin 43: 234-240. DOI 10.1007/BF03214993.

Yin HT, Zhang XL, Wu XE, Chen HG (2013). In vivo evaluation of curcumin-loaded nanoparticles in a A549 xenograft mice model. Asian Pacific Journal of Cancer Prevention 14: 409412. DOI 10.7314/APJCP.2013.14.1.409.

Yusuf M, Khan RA, Ahmed KM (2012). Plausible antioxidant biomechanics and anticonvulsant pharmacological activity of brain-targeted $\beta$-carotene nanoparticles. International Journal of Nanomedicine 7: 4311-4321. DOI 10.2147/IJN. S34588. 